\title{
Intravenous oxytocin bolus and infusion versus infusion alone on the blood loss during caesarean section
}

\author{
Priyanka Mathe $^{1}$, Suniti Kale ${ }^{2 *}$, Aruna Batra ${ }^{1}$, Achla Batra ${ }^{1}$, Shipra Aggrawal ${ }^{2}$, \\ Abhishek Nagarajappa ${ }^{3}$
}

\begin{abstract}
${ }^{1}$ Department of Obstetrics and Gynecology, VMMC and Safdarjung Hospital, New Delhi, India
${ }^{2}$ Department of Anaesthesia, VMMC and Safdarjung Hospital, New Delhi, India

${ }^{3}$ Department of Anaesthesia, All India Institute of Medical Sciences, New Delhi, India
\end{abstract}

Received: 02 October 2019

Accepted: 13 November 2019

\author{
*Correspondence: \\ Dr. Suniti Kale, \\ E-mail: findsuniti@gmail.com
}

Copyright: (c) the author(s), publisher and licensee Medip Academy. This is an open-access article distributed under the terms of the Creative Commons Attribution Non-Commercial License, which permits unrestricted non-commercial use, distribution, and reproduction in any medium, provided the original work is properly cited.

\section{ABSTRACT}

Background: PPH is one of the leading causes of maternal mortality in the world. In India $>30 \%$ maternal mortality is because of PPH.

Methods: 250 females posted for LSCS were randomised into 2 groups. Group A: 5 U oxytocin bolus $+40 \mathrm{U}$ oxytocin infusion@125 ml/hour in $500 \mathrm{ml}$ saline. Group B: $5 \mathrm{ml}$ Saline bolus + 40 U oxytocin infusion

Primary outcome was to measure blood loss (objective and subjective). Secondary outcomes were time for uterine hardening, additional uterotonic agents, hemodynamic changes, side effects and need for blood transfusion within 24 hours of LSCS.

Results: Blood loss was significantly less in Group A in objective as well as subjective assessment $(p<0.001)$. Requirement for additional oxytocin bolus was significantly higher in Group B as compared Group A ( $\mathrm{p}=0.025$ ). Postoperative hematocrit of Group A was higher than that of Group B ( $<<0.001)$. Transfusion requirement was significantly higher $(\mathrm{p}=0.04)$ in Group B $(9.6 \%$ versus $3.2 \%)$. There was no significant difference in hemodynamics between the groups in the intraoperative period $(\mathrm{p}>0.05)$. However, during the postoperative period increase in heart rate was noted in Group B ( $<<0.05)$. Vomiting was the only major side effect observed, which was higher in Group A $(5.6 \%$ versus $3.2 \%)$.

Conclusions: Combination of $5 \mathrm{U}$ oxytocin bolus followed by an infusion of $40 \mathrm{U}$ oxytocin given over 4 hours routinely in ASA grade I and ASA grade II parturient significantly decreases the operative blood loss during LSCS without causing any hemodynamic variability. This regimen provides better uterine contractility, lesser need for additional utero-tonic agents and lesser requirement of blood transfusion.

Keywords: Hemodynamic variation, Lower (uterine) segment caesarean section, Maternal mortality, Objective blood loss, Oxytocin, Post-partum haemorrhage, Subjective blood loss

\section{INTRODUCTION}

Postpartum haemorrhage (PPH) is one of the major contributors in maternal mortality worldwide, accounting for up to $30 \%$ of maternal deaths. ${ }^{1}$ The blood loss during caesarean is much more compared to vaginal delivery and every attempt should be made to reduce it. WHO recommends uterotonics for prevention of $\mathrm{PPH}$ during the third stage of labor in all births, the drug of choice being Oxytocin $10 \mathrm{IU}$ IM/IV. ${ }^{2}$ The recommendations are more widely accepted for vaginal delivery; and both IV infusion and IV bolus have been shown to have no safety 
concerns after vaginal delivery. ${ }^{3}$ However, there are concerns about the hemodynamic changes associated with bolus dose of oxytocin during caesarean section. ${ }^{4}$ The practice in United States is to use oxytocin infusion alone, whereas the standard practice among the obstetricians and anaesthetists in UK is the use of IV bolus 5-10 U and the Royal college of Obstetricians also recommends $5 \mathrm{U} \mathrm{I} / \mathrm{V}$ oxytocin bolus alone after cord clamping, even though oxytocin has a short half-life of 4 10 minutes. $^{5-7}$ So there is still uncertainty around the optimal dose and route at caesarean section; intravenous bolus, intramuscular, or infusion. ${ }^{8}$

Sheehan et al, had suggested that combined bolus and infusion may be better than bolus alone due to possibly different mechanism of actions; the bolus leading to placental separation by constriction of venous sinuses and placental bed haemostasis, while an infusion maintains uterine contractility throughout the surgical procedure and immediate postpartum period. ${ }^{9}$ The present study was designed to evaluate the use of 'IV oxytocin bolus (5 IU) combined with infusion' for reduction in blood loss during caesarean section and associated hemodynamic changes compared to 'infusion alone'.

\section{METHODS}

This double-blind placebo controlled randomized study was conducted in the department of obstetrics and gynaecology VMMC and $\mathrm{SJH}$ in collaboration with department of anaesthesia, following hospital ethical committee clearance. A Sample size of 125 subjects in each group was calculated, assuming that $30 \%$ of 'infusion alone' group would require additional uterotonics compared with $20 \%$ in 'bolus and infusion' oxytocin group with $\alpha=0.05$ and power $=85 \%$.

A total 250 women posted for LSCS (Elective/Emergency) under subarachnoid block, as singleton term pregnancy, with $\mathrm{Hb} \geq 10 \mathrm{gm} \%$, belonging to ASA I or II, were included in the study. Those at high risk for PPH such as placenta previa, coagulopathies, thrombocytopenia, grand multiparity, fibroid uterus, hydramnios, PIH, severe systemic disease, and those on anticoagulants or with history of previous obstetric haemorrhage were excluded from the study. Following a written informed consent, the patients were randomized using closed envelope method into 2 groups: Group A (n $=125$ ) 'infusion alone': received IV bolus of oxytocin and oxytocin infusion while Group B $(n=125)$ 'Bolus and infusion': received IV bolus of saline (placebo) and oxytocin infusion.

All patients underwent a thorough pre-anaesthetic evaluation as per the protocol for obstetric anaesthesia. Before starting LSCS, a record was made of patient's weight and baseline haemodynamic parameters i.e. Heart rate $(\mathrm{PR})$, non-invasive blood pressure (SBP, MAP, $\mathrm{DBP})$, and oxygen saturation ( $\mathrm{SpO} 2)$; along with collection of sample for preoperative haematocrit estimation. All patients received subarachnoid block at L2/L3 or L3/L4 interspace with $1.8-2 \mathrm{ml}$ of $0.5 \%$ bupivacaine (heavy) with $10 \mu \mathrm{g}$ fentanyl using $25 \mathrm{G}$ spinal needle while co-loading with $1000 \mathrm{ml}$ of ringer lactate. The sensory and motor levels of the block were noted.

Surgical procedure was standardized and all cases were done by senior obstetrician. The abdomen was opened using a Pfannenstiel incision. Bolus injection (5 IU oxytocin diluted to $5 \mathrm{ml}$ saline in Group A; $5 \mathrm{ml}$ saline as placebo in Group B) was given over 20 seconds at cord clamping followed by IV infusion of oxytocin 40 IU in $500 \mathrm{ml}$ saline over 4 hours in both the groups @ $125 \mathrm{ml} / \mathrm{hr}$. Both the anaesthetist and the surgeon were blinded to the contents of bolus. The time between cord clamping and initial strong contraction of uterus was noted. Placental delivery was done via controlled cord traction and uterus was closed in two layers. Exteriorization of uterus was avoided unless clinically indicated. Subjective assessment of blood loss was done by the anaesthetist and the surgeon based on soakage of surgical mops and volume in the suction drain.

Uterine tone was assessed by the surgeon using Likert Scale (0-4) as 0-floppy, 1-soft, 2-poorly contracted, 3well contracted, 4-hard rock. In case of inadequate uterine tone (Likert Scale 0, 1, 2), additional rescue uterotonic were given. Oxytocin bolus 5U IV was used as the first rescue uterotonic, and inj. Methyl ergometrine (0.2 mg) or Inj. 15-methyl PGF $2 \alpha$ (250 mcg.) or multiple uterotonics if poor contractility continued.

Hemodynamic (BP, HR, NIBP, $\mathrm{SpO}_{2}$ ) were recorded intraoperatively every 2 mins for 10 mins after oxytocin bolus and every 5 mins for rest of LSCS; post-operatively every 15 mins for one hour, and every 30 mins for next 3 hours. A change of $20 \%$ from baseline was considered significant for all parameters. Side effects like nausea, vomiting, chest pain were noted. Number of blood transfusions required within 24 hours of surgery was also noted.

Haematocrit was re-estimated 48 hours after LSCS to provide an adequate interval for hemodynamic equilibrium; Objective (Calculated) estimation of blood loss was made as per Carvalho and Shook's formula; ${ }^{10}$

\section{$E B L c a l c=\underline{E B V} \times($ Pre op HcT - Post op HcT $)$ Pre op HcT}

- $\quad$ EBLcalc (Calculated estimated blood loss)

- $\quad$ EBV (Estimated blood volume $)=$ Booking weight in $\mathrm{kg} \times 85$

- $\quad$ HcT (Haematocrit)

\section{Outcome measures}

Primary outcome measure was estimated blood loss (objective and subjective). Secondary outcomes were 
time from cord clamping to uterine hardening; need for additional uterotonic agents; hemodynamic changes (PR, $\mathrm{BP}, \mathrm{HR}, \mathrm{SpO}_{2}$ ); side effects (headache, vomiting, chest pain) and the need for blood transfusion within 24 hours of LSCS.

\section{RESULTS}

Patient characteristics including the mean age and parity, pre-operative vital parameters, haematocrit and the indications for LSCS were comparable between the study and control groups (Table 1).

The amount of blood loss was much less in Group A patients as compared to Group B (Table 2), the difference being highly significant in objective terms (estimated blood loss) as well as subjective (visual assessment) of blood loss ( $\mathrm{p}<0.001)$. The subjective and objective assessments of blood loss were comparable.

There was no significant difference in the time lapse between cord clamping and initial uterine contraction in the two groups $(p=0.360)$. However, the number of women with well contracted uterus Likert grade 3/4 was significantly higher $(\mathrm{p}=0.045)$ and those with poorly contracted uterus grade $1 / 2$ was significantly less ( $\mathrm{p}=$ 0.004) in Group A compared to Group B; even though there was no difference in the frequency of floppy uterus grade 0 , the incidence being $5.0 \%$ in both the groups (Table 3).

Table 1: Patient characteristics.

\begin{tabular}{|lll|}
\hline Parameter & $\begin{array}{l}\text { Group A oxytocin IV bolus }+ \\
\text { infusion }(\mathbf{n}=\mathbf{1 2 5})\end{array}$ & $\begin{array}{l}\text { Group B oxytocin infusion alone } \\
(\mathbf{n}=\mathbf{1 2 5})\end{array}$ \\
\hline Mean maternal Age, years (SD) & $25.04(3.45)$ & $24.47(3.65)$ \\
\hline Primigravidae, no. $(\%)$ & $82(65.6 \%)$ & $68(54.4 \%)$ \\
\hline Indication for LSCS, no. (\%) & & $57(45.6 \%)$ \\
\hline Fetal distress & $48(38.4 \%)$ & $22(17.6 \%)$ \\
\hline Non progress of labor & $20(25.0 \%)$ & $14(11.2 \%)$ \\
\hline Breech/transverse lie & $15(12.0 \%)$ & $32(25.6 \%)$ \\
\hline Others & $42(33.6 \%)$ & $86.57(10.92)$ \\
\hline Mean Preop. Pulse, rate/min (SD) & $84.50(8.65)$ & $116.82(10.79)$ \\
\hline Preop. systolic BP, mmHg (SD) & $117.64(7.95)$ & $90.68(17.86)$ \\
\hline Preop. diastolic BP, mmHg (SD) & $89.89(20.51)$ & $99.24(12.64)$ \\
\hline Preoperative MAP, mmHg (SD) & $98.70(15.88)$ & \\
\hline
\end{tabular}

Table 2: Pre- and Post-operative hematocrit, estimated blood loss.

\begin{tabular}{|llll|}
\hline \multicolumn{1}{|c|}{ Parameter } & $\begin{array}{l}\text { Group A }(\mathrm{n}=125) \text { oxytocin IV } \\
\text { bolus + infusion Mean (SD) }\end{array}$ & $\begin{array}{l}\text { Group B }(\mathrm{n}=125) \text { oxytocin } \\
\text { infusion alone Mean (SD) }\end{array}$ & p value \\
\hline Pre Op. Hematocrit & $34.97(3.45)$ & $34.30(2.86)$ & 0.096 \\
\hline Post Op. Haematocrit 48-hour post-LSCS & $30.82(3.29)$ & $28.90(2.93)$ & $<0.001$ \\
\hline Blood loss (mL) objective (estimated) & $844.37(189.15)$ & $1076.90(241.45)$ & $<0.001$ \\
\hline Subjective (visual assessment) & $891.94(226.62)$ & $1100.80(224.15)$ & $<0.001$ \\
\hline
\end{tabular}

Table 3: Uterine contractility, need for uterotonics and blood transfusion.

\begin{tabular}{|c|c|c|c|}
\hline Parameter & $\begin{array}{l}\text { Group A }(n=125) \text { oxytocin IV } \\
\text { Bolus + infusion }\end{array}$ & $\begin{array}{l}\text { Group B }(n=125) \\
\text { oxytocin infusion alone }\end{array}$ & p value \\
\hline \multicolumn{4}{|c|}{ Oxytocin bolus to initial uterine contraction } \\
\hline Time lapse, seconds Mean (SD) & $60.64(13.30)$ & $62.35(16.10)$ & 0.36 \\
\hline \multicolumn{4}{|l|}{ Uterine tone } \\
\hline Floppy (likert grade 0) & $5(4.0 \%)$ & $5(4.0 \%)$ & 1.000 \\
\hline Poorly contracted (gr. 1,2) & $5(4.0 \%)$ & $18(14.4 \%)$ & 0.004 \\
\hline Well contracted (gr. 3,4$)$ & $115(92.0 \%)$ & $102(81.6 \%)$ & 0.045 \\
\hline \multicolumn{4}{|l|}{ Additional uterotonics } \\
\hline Only oxytocin & $8(6.4 \%)$ & $19(15.2 \%)$ & 0.025 \\
\hline Inj. Methlyergometrine & $0(0.0 \%)$ & $1(0.8 \%)$ & 0.316 \\
\hline Multiple & $1(0.8 \%)$ & $5(4.0 \%)$ & 0.098 \\
\hline Need for blood transfusion & $4(3.2 \%)$ & $12(9.6 \%)$ & 0.04 \\
\hline
\end{tabular}


The requirement for additional oxytocin bolus was significantly higher in Group B as compared Group A (p $=0.025)$, however, the requirement for second line rescue uterotonics was not significantly different (Table 3). Blood transfusion requirement was also significantly higher $(\mathrm{p}=0.04)$ in Group B $(9.6 \%)$ compared to that in Group A (3.2\%).

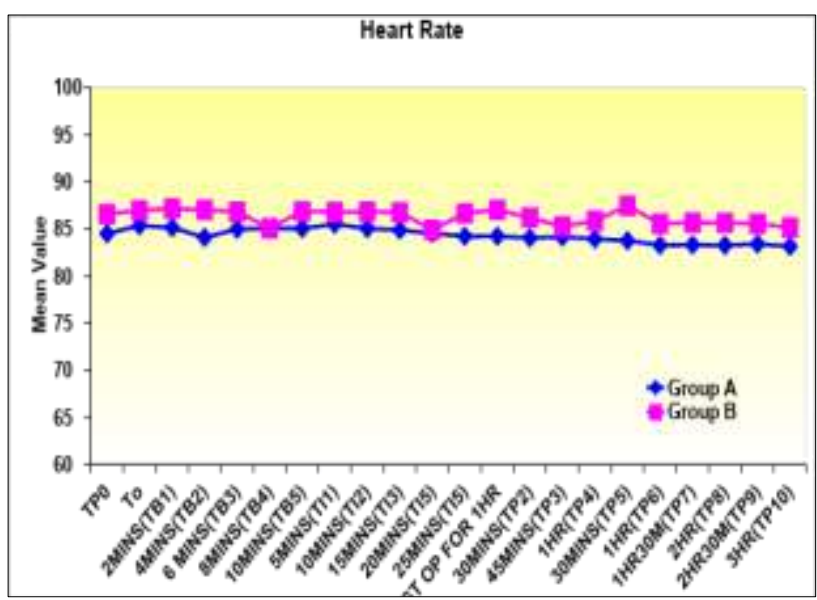

Figure 1: Heart rate through the study period.

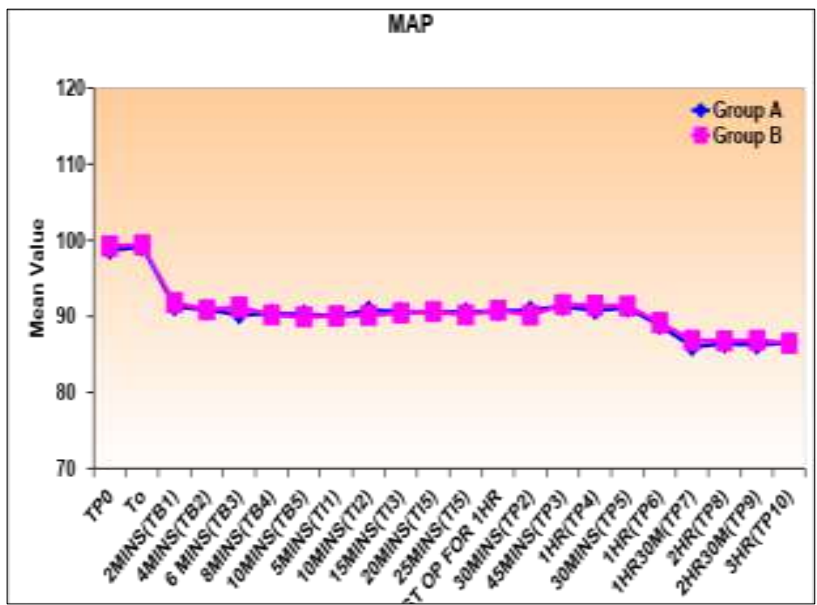

Figure 2: MAP through the study period.

Monitoring of hemodynamic variables showed no significant difference in the heart rate as well as systolic/diastolic BP and MAP throughout intra operative period in the two groups ( $p>0.05)$. However, during the postoperative period slight increase in heart rate was noted in Group B ( $\mathrm{p}<0.05)$, but the BP showed no significant change (Figure 1,2). Vomiting was the only major side effect observed, which was higher in Group A $(5.6 \%)$ compared to Group B $(3.2 \%)$.

\section{DISCUSSION}

We found that the 'bolus and infusion' group had significantly less blood loss compared to the 'infusion alone' group assessed subjectively as well as objectively, mean(SD) blood loss being $844.37 \pm 189.15 \mathrm{ml}$ versus
$1076.90 \pm 241.45 \mathrm{ml}$ respectively ( $\mathrm{p} \leq 0.001$ ). Objective assessment is a more accurate method of evaluating intraoperative blood loss especially during caesarean section because the soaking of mops as well as the collection in the suction drain gets diluted with amniotic fluid. (Other studies that have also used objective blood loss assessment.) Murphy et al's pilot study compared blood loss in elective LSCS in two groups receiving 5U oxytocin 'bolus alone' versus 5U oxytocin 'bolus and $30 \mathrm{U}$ oxytocin infusion' and found the total mean estimated blood loss to be lower in oxytocin 'infusion and bolus' compared to 'bolus alone' (567 ml versus 624 $\mathrm{ml}$ ); also fewer women had a major haemorrhage., ${ }^{9,11}$ However, Sheehan et al, reported no significant difference in the occurrence of major obstetric haemorrhage as well as mean blood loss amongst the two groups in a study of similar design conducted on a much larger population. ${ }^{9}$ King et al, compared oxytocin 'bolus plus infusion' with oxytocin 'infusion alone' as in our study, however, this trial was limited to patients at high risk of uterine atony, with neither surgery nor anaesthesia standardized and blood loss was estimated visually. ${ }^{12}$ Detailed hemodynamic and need for blood transfusions was also not compared.

We found no significant difference in the time lapse between cord clamping and initial uterine contraction, may be because the initial contraction of uterus occurs even before the effect of IV bolus oxytocin appears. This may imply that the bolus oxytocin does not affect the timing of placental separation. No other study has compared this parameter.

During surgery the uterus was found to be adequately contracted (Likert Scale 3,4) in higher number of subjects in Group A $(92.0 \%)$ than Group B $(81.6 \%)(p=0.045)$; while it was poorly contracted in only $4.0 \%$ subjects in group A compared to $14.4 \%$ in Group B ( $p=0.004)$. Floppy tone was found in $5.0 \%$ individuals in both groups which may point towards other obstetric causes for this condition. King et al, also found a significant difference in uterine tone immediately after placental delivery $(p<0.01)$ which disappeared after 5 minutes. ${ }^{12}$ This suggests that oxytocin bolus does improve the uterine tone but probably has little effect on this extreme degree of uterine atony. Other studies did not comment on the uterine tone. ${ }^{9,11}$

In the present study, less number of women in 'bolus and infusion' group required additional uterotonics compared to 'infusion alone' group, the difference being significant only for first line rescue i.e. bolus oxytocin $(6.4 \%$ versus $15.2 \%, \mathrm{p} 0.025)$. King et al, found no difference in additional utero-tonic drugs in first 24 hours between the 'infusion' versus 'infusion and bolus' group. ${ }^{12}$ However, highly significant difference $(\mathrm{p}<0.001)$ was noted by Sheehan et al and Murphy et al while comparing the need for additional utero-tonic agent in the 'bolus and infusion' group and the 'bolus only' group (12.2\% versus $18.4 \%$ and $5.0 \%$ versus $11.0 \%$ ) respectively signifying 
the importance of infusion in maintaining uterine contractility..$^{9,11}$

A significant difference was recorded in the number of blood transfusions between group A and B (3.2\% versus $9.6 \%, \mathrm{p}=0.04)$. Other studies, however, found no significant difference between the 'combined bolus and infusion' versus 'bolus alone' or 'infusion alone' groups. ${ }^{9,12}$ There was no significant difference in the peroperative heart rates between the two groups, however, the 'bolus and infusion' group showed a slight increase in heart rate in the postoperative period, which though significant statistically, was not eventful clinically

Abdullah et al, studied the hemodynamic effects of $5 \mathrm{U}$ oxytocin intravenous bolus given over 1 second and compared with $5 \mathrm{U}$ diluted to $20 \mathrm{ml}$ normal saline given over 5 minutes; and found statistically significant difference in heart rate and mean arterial pressure ( $\mathrm{P}$ $<0.001$ ) over 1 to 15 minutes. ${ }^{13}$ Our study found no significant difference in systolic or diastolic blood pressure as well as mean arterial pressure between Group A and Group B, possibly because the bolus injection was diluted to $5 \mathrm{ml}$ saline and given over $20 \mathrm{sec}$. Other studies using oxytocin bolus did not compare the hemodynamic variables. ${ }^{9,11,12}$

The only major side effect observed in our study was vomiting which was seen in $3.2 \%$ in Group A and $5.6 \%$ in Group B $(p=0.355)$. The side effects like hypotension, dysrhythmias and ECG changes were not seen in any subject. No significant side effects were noted in other studies as well..$^{9,11,12}$

\section{CONCLUSION}

We conclude that a combination of $5 \mathrm{U}$ oxytocin bolus (given at time of cord clamping) followed by an infusion of $40 \mathrm{U}$ oxytocin given over 4 hours routinely in ASA grade I and ASA grade II parturient significantly decreases the operative blood loss during LSCS without causing any hemodynamic variability or any other untoward effect. This regimen provides better uterine contractility, lesser need for additional utero-tonic agents and lesser requirement of blood transfusion.

Funding: No funding sources Conflict of interest: None declared

Ethical approval: The study was approved by the Institutional Ethics Committee

\section{REFERENCES}

1. Say L, Chou D, Gemmill A, Tunçalp Ö, Moller AB, Daniels $J$, et al. Global causes of maternal death: a WHO systematic analysis. Lancet Glob Health. 2014;2(6):e323-33.
2. WHO. WHO recommendations for the prevention and treatment of postpartum haemorrhage. Geneva: Dept. of reproductive health and research. WHO; 2012:1-41.

3. Charles D, Anger H, Dabash R, Darwish E, Ramadan MC, Mansy A, et al. Intramuscular injection, intravenous infusion, and intravenous bolus of oxytocin in the third stage of labor for prevention of postpartum hemorrhage: a three-arm randomized control trial. BMC Preg Child. 2019;19(1):38.

4. Thomas JS, Koh SH, Cooper GM. Haemodynamic effects of oxytocin given as i.v bolus or infusion on women undergoing caesarean section. $\mathrm{Br} \mathrm{J}$ Anaesth. 2007;98:116-9.

5. ACOG Practice Bulletin: Clinical Management Guidelines for Obstetrician-Gynecologists Number 76, October 2006: postpartum hemorrhage. Obstet Gynecol. 2006;108(4):1039-47.

6. Sheehan SR, Wedisinghe L, Macleod M, Murphy DJ. Implementation of guidelines on oxytocin use at caesarean section: a survey of practice in Great Britain and Ireland. Eur J Obstet Gynecol Reprod Biol. 2010;148(2):121-4.

7. Mavrides E, Allard S, Chandraharan E, Collins P, Green L, Hunt BJ, et al. on behalf of the Royal College of Obstetricians and Gynaecologists. Prevention and management of postpartum haemorrhage. BJOG. 2016;124:e106-e149.

8. Gallos ID, Papadopoulou A, Man R, Athanasopoulos N, Tobias A, Price MJ, et al. Uterotonic agents for preventing postpartum haemorrhage: a network metaanalysis. Cochrane Database Syst Rev. 2018;12:CD011689.

9. Sheehan SR, Montgomery AA, Carey M, McAuliffe FM, Eogan M et al. Oxytocin bolus versus oxytocin bolus and infusion for control of blood loss at elective caesarean section: double blind placebo controlled randomised trial. BMJ. 2011;343:1-11.

10. Shook PR, Schultz JR, Reynolds JD, Barbara P, Spahn TE, DeBalli P. Estimating blood loss for cesarean section - how accurate are we Anesthesiol. 2003;98:1.

11. Murphy DJ, MacGregor H, Munishankar B, McLeod G. A randomised controlled trial of oxytocin 5IU and placebo infusion versus oxytocin 5IU and 30IU infusion for the control of blood loss at elective caesarean section- pilot study. Eur J Obstet Gynecol Reprod Biol. 2009;142(1):30-3.

12. King KJ, Douglas MJ, Unger W, Wong A, Robert A. R. Five-unit bolus oxytocin at caesarean delivery in women at risk of atony: a randomized, double-blind, controlled trial. 2010;111:1460-6.

13. Abdullah M, Khurshid T, Raheel, Ghauri A, Abassi T. Oxytocin iv bolus vs infusion; haemodynamic effects in women undergoing caesarean section. Prof Med J. 2012;19(3)

Cite this article as: Mathe $\mathrm{P}$, Kale $\mathrm{S}$, Batra A, Batra A, Aggrawal S, Nagarajappa A. Intravenous oxytocin bolus and infusion versus infusion alone on the blood loss during caesarean section. Int J Reprod Contracept Obstet Gynecol 2019;8:4824-8. 